\title{
Swimming regulations for protein kinase A catalytic subunit
}

Matthew G. Gold ${ }^{\mathrm{a}, 1}$

a Department of Neuroscience, Physiology \& Pharmacology, University College London, Gower Street, LONDON, WC1E 6BT, UK

${ }^{1}$ Correspondence: $\underline{\text { m.gold@ucl.ac.uk }}$

Keywords: Protein Kinase A, anchoring, cAMP, signalling 


\begin{abstract}
cAMP-dependent protein kinase (PKA) plays a central role in important biological processes including synaptic plasticity and sympathetic stimulation of the heart. Elevations of cAMP trigger release of PKA catalytic (C) subunits from PKA holoenzymes, thereby coupling cAMP to protein phosphorylation. Uncontrolled $\mathrm{C}$ subunit activity, such as occurs in genetic disorders in which regulatory subunits are depleted, is pathological. Anchoring proteins that associate with PKA regulatory subunits are important for localising PKA activity in cells. However, anchoring does not directly explain how unrestrained "free swimming" of C subunits is avoided following C subunit release. In this review, I discuss new mechanisms that have been posited to account for this old problem. One straightforward explanation is that cAMP does not trigger $\mathrm{C}$ subunit dissociation but instead activates intact PKA holoenzymes whose activity is restrained through anchoring. A comprehensive comparison of observations for and against cAMP-activation of intact PKA holoenzymes does not lend credence to this mechanism. Recent measurements have revealed that PKA regulatory subunits are expressed at very high concentrations, and in large molar excess relative to $\mathrm{C}$ subunits. I discuss the implications of these skewed PKA subunit concentrations, before considering how phosphorylation of type II regulatory subunits and myristylation of $\mathrm{C}$ subunits are likely to contribute to controlling $\mathrm{C}$ subunit diffusion and re-capture in cells. Finally, I speculate on future research directions that may be pursued on the basis of these emerging mechanisms.
\end{abstract}




\section{Introduction}

cAMP-dependent protein kinase, also known as protein kinase A (PKA), is the major intracellular receptor for the ubiquitous second messenger cAMP. Phosphorylation of protein substrates by PKA catalytic (C) subunits following cAMP activation is a critical link in cAMP-mediated regulation of diverse cellular processes including sympathetic stimulation of the heart [1,2], hormonal enhancement of pancreatic insulin release [3] and glycogen breakdown [4], maintenance of lens transparency [5], and synaptic plasticity [6]. PKA holoenzymes comprise regulatory subunit homodimers that bind and inhibit $\mathrm{C}$ subunits. cAMP triggers the release of $\mathrm{C}$ subunits by binding to two sites on each regulatory subunit. PKA may be divided into two types based on which regulatory $(R)$ subunit isoform sequesters the catalytic subunits. Type I PKA (RI $\alpha$ or RI $\beta)$ is predominantly cytosolic, and there is evidence that PKA of this type is more important in regulating nuclear $\mathrm{C}$ subunit entry for regulation of gene expression [7, 8]. Type II PKA (RII $\alpha$ or RII $\beta$ ) is enriched in the particulate fraction [9]. Each regulatory subunit isoform assembles PKA holoenzymes with a unique quaternary structure $[10,11]$, reflecting the different functions of each isoform. For example, RII $\beta$ knockout mice are lean [12] and not susceptible to diet-induced insulin resistance [13], whereas knockout of RI $\alpha$ is lethal at the embryonic stage [14]. RIa plays a housekeeping role across cell types by increasing in abundance in response to chronic elevations of PKA activity [14]. The two major $\mathrm{C}$ subunit isoforms $(\mathrm{C} \alpha, \mathrm{C} \beta)$ are $93 \%$ identical in humans $[10,15]$. Experiments using fluorescent reporters of cAMP concentration [16, 17] and PKA activity [18, 19] have corroborated earlier studies indicating that cAMP signals are localised and PKA activity is directed towards specific substrates in cells $[20,21]$. Understanding how this signalling specificity is achieved has been a major focus of cAMP and PKA research over the last three decades. A key role for A-kinase anchoring proteins (AKAPs) has emerged from these research efforts.

AKAPs, which were initially identified as contaminants of PKA RII subunit preparations [22], present amphipathic anchoring helices that associate with the dimerisation and docking (D/D) domain at the N-terminus of PKA regulatory subunits $[23,24]$. AKAPs typically have a binding preference for RII over RI subunits, and are often themselves 
attached to cellular membranes [25], which partly explains the enrichment of type II PKA in particulate cell fractions [9]. According to the AKAP model, activation of anchored PKA leads to the release of $\mathrm{C}$ subunits that preferentially phosphorylate substrates in the vicinity of the AKAP-PKA complex before recapture. Several AKAPs also bind directly to other components of the cAMP signalling cascade, including adenylyl cyclases [26] and phosphodiesterases $[27,28]$. In these cases, the local coordination of enzymes that synthesise, degrade, and respond to cAMP is thought to enable precise spatial and temporal control of cAMP/PKA signalling [29, 30]. However, our current conceptions of localised cAMP/PKA signalling contain an essential shortcoming: there is no clearly defined mechanism for restricting PKA $\mathrm{C}$ subunits after their release. This problem was encapsulated by Ted Rall over forty years ago who observed that following PKA activation we are presented with "the unsatisfying picture of the catalytic subunit of protein kinase swimming about, happily phosphorylating a variety of cellular constituents whether they need it or not"'[31].

One simple and appealing explanation to solve this problem, which has received intermittent support, is that cAMP does not in fact trigger dissociation of PKA C subunits from anchored RII subunits. According to this mechanism, $\mathrm{C}$ subunits are able to access and phosphorylate local substrates while remaining in complex with RII upon cAMP activation. In this review, I first weigh up evidence for and against PKA activation without C subunit dissociation. I go on to consider alternative mechanisms that are emerging to regulate $\mathrm{C}$ subunit swimming within cells, including the relative stoichiometries of PKA $\mathrm{R}$ and $\mathrm{C}$ subunits, phosphorylation of the RII subunit inhibitor sequence (IS), and membrane insertion of myristylated $\mathrm{C}$ subunits.

\section{Assessment of evidence for PKA activation without $\mathrm{C}$ subunit dissociation}

The textbook mechanism of PKA activation via cAMP-induced dissociation of $\mathrm{C}$ subunits arose from studies in the 1970s showing that cAMP releases C subunits from both type I and type II holoenzymes according to cation exchange [32], affinity to casein-sepharose 
[33] and cAMP agarose [34, 35], size exclusion chromatography [36, 37], and sucrose gradient ultacentrifugation [38]. Further in vitro data supporting cAMP-induced C subunit dissociation has been provided by small angle x-ray scattering [39], and AlphaScreen experiments [40]. The only in vitro study showing no dissociation of $\mathrm{C}$ subunit by cAMP involved time-resolved emission anisotropy measurements of carboxyfluorescein-labelled $\mathrm{C}$ subunit $\left({ }^{\mathrm{CF}} \mathrm{C}\right)$. The authors [41], following up on earlier FRET experiments [42], found that adding $50 \mu \mathrm{M}$ cAMP to $\mathrm{RII}^{-{ }^{\mathrm{CF}}}{ }^{\mathrm{C}}$ holoenzymes did not significantly reduce the rotational mobility of ${ }^{\mathrm{CF}} \mathrm{C}$ indicating that cAMP had not triggered $\mathrm{C}$ subunit release. It should be noted that non-specific labeling of the $\mathrm{C}$ subunit with carboxyfluorescein may have blocked the effect of phosphorylation [43] in the IS to prevent complete dissociation in this experiment (see 'Final Comments' in [44]). The balance of data from experiments in living cells also supports a dissociative activation mechanism. FRET measurements between RI/RII subunits and C subunits based on microinjection [45, 46], and geneticallyencoded fluorophores $[47,48]$ are consistent with cAMP rises triggering the dissociation of $\mathrm{C}$ subunits. Further evidence of $\mathrm{C}$ subunit dissociation is provided by two-photon fluorescence lifetime imaging microscopy (2p-FLIM) [49], UV crosslinking [50], proximity ligation assays [51], and bioluminescence resonance energy transfer (BRET) experiments [40, 52]. In support of non-dissociative cAMP activation, isoproterenol does not reduce co-immunoprecipitation of $\mathrm{C}$ subunits with either AKAP79-RII [51, 53] or AKAP18-RII complexes [51]. However, UV crosslinking experiments show that in this experiment $\mathrm{C}$ subunits likely re-associate with RII subunits following cell lysis during the immunoprecipitation process after the cAMP signal has been diluted/degraded [50]. Overall, the weight of evidence strongly supports cAMP-induced C subunit dissociation. Observations supporting dissociative and non-dissociative activation are summarised in Table 1.

Although cAMP induces $\mathrm{C}$ subunit dissociation in cells, quantitative 2p-FLIM experiments show that physiologically-relevant concentrations of norepinephrine support only a $\sim 12 \%$ increase in the level of free $\mathrm{C}$ subunits in CA1 hippocampal neurons [49]. Is it possible that some intact type II holoenzymes also act as protein kinases during sub-maximal stimulations such as this? cAMP is thought to trigger $\mathrm{C}$ subunit release via an intermediate 
in which both cyclic nucleotide binding (CNB) domains of the R subunit are occupied while it remains bound to the $C$ subunit (Figure 1) [54, 55]. Indeed, R-C-2cAMP complexes have been recorded in native MS experiments [51]. Since these complexes are a predicted intermediate in $\mathrm{C}$ subunit dissociation $[54,55]$, their identification is not proof that cAMP does not dissociate $\mathrm{C}$ subunits from $\mathrm{R}$ subunits, but it is worth considering whether these intermediates could phosphorylate substrates. The two major interfaces between R and C subunits - observed in both RI-C [56] and RII-C [57] crystal structures are between (i) the CNB domains of the R subunit (blue, Fig. 1A) and elements of the $\mathrm{C}$ subunit large lobe including the G helix and activation loop (green, Fig. 1A) (ii) the IS of the $\mathrm{R}$ subunit and the substrate binding groove of the $\mathrm{C}$ subunit (Fig. 1A). Binding of two copies of cAMP to the CNB domains changes their relative orientations [56-58], thereby disrupting their interface with the $C$ subunit (Fig. 1B). Dissociation of the IS from the $C$ subunit in this ternary 2cAMP-R-C results in simultaneous disinhibition and dissociation of the $\mathrm{C}$ subunit (Fig. 1C). A cAMP-activated holoenzyme would require that the CNB domains in the $\mathrm{R}$ subunit are occupied by cAMP in such a way as to propagate an allosteric rearrangement that releases the IS from the $\mathrm{C}$ subunit while maintaining an $\mathrm{R}-\mathrm{C}$ interface that prevents dissociation. Experiments in genetically-engineered cells lacking PKA Ca, RII $\alpha$ and RII $\beta$ subunits show that RII $\alpha$ and $C \alpha$ subunits fused by a synthetic 33-amino acid linker can be activated in cells by, e.g., $1 \mu \mathrm{M}$ isoproterenol [51]. However, these fusions do not serve as a realistic model of active holoenzymes since, in these synthetic constructs, IS release is possible without $\mathrm{C}$ subunit dissociation since the subunits are additionally tethered by a synthetic covalent linker (Fig. 1D). By mutating the arginines in the inhibitor site of RII, it is possible to generate intact synthetic PKA holoenzymes that are active in the absence of cAMP [59]. However, from our current knowledge of PKA structure, it is difficult to conceive of a mechanism by which cAMP binding could allosterically release the IS without triggering $C$ subunit release. In sum, existing data (Table 1) show that cAMP triggers $\mathrm{C}$ subunit dissociation in vitro an in vivo, and there is currently no compelling evidence that cAMP can trigger phosphorylation via intact PKA holoenyzmes.

\section{$R$ subunits are expressed at high concentrations in molar excess of $C$ subunits}


Once $\mathrm{C}$ subunits are released, their range of action will be determined by their diffusion rate and their rate of recapture. A key determinant of recapture rate is the availability of unoccupied regulatory subunits. Theoretically, fast recapture will be supported by high concentrations of $\mathrm{R}$ subunits. Faster recapture of $\mathrm{C}$ subunits at higher $\mathrm{R}$ subunit concentrations is exemplified by an in vitro binding study which showed that a higher proportion of $\mathrm{C}$ subunits associate with $\mathrm{R}$ subunits when total $\mathrm{R}$ subunit concentration is raised in the presence of $50 \mu \mathrm{M}$ cAMP [7]. Recent experimental measurements reveal that $\mathrm{R}$ subunits are indeed present at very high cellular concentrations. Quantitative immunoblotting of PKA subunits present in protein extracts from human embryonic kidney (HEK)-293T cells [50] shows that these cells contain $\sim 1.5 \mu \mathrm{M}$ RII, $\sim 0.6 \mu \mathrm{M}$ RI, and $\sim 0.2$ $\mu \mathrm{MC}$ subunits. Analysis of PKA subunits in protein extracts from rat by the same approach revealed very high concentrations of R subunits, e.g., in forebrain $(608 \mathrm{ng} / \mathrm{mg}$ total protein for RI, $3266 \mathrm{ng} / \mathrm{mg}$ RII), and large ( $\sim 15$-fold) molar excesses of R to C subunits in every tissue examined [50]. A different study, employing quantitative proteomic analysis of human left ventricle [60], detected a similar skewed stoichiometry with both dominant $\mathrm{R}$ subunit isoforms in cardiac tissue (RI $\alpha$ at $538 \mathrm{ng} / \mathrm{mg}$; RII $\alpha$ at $404 \mathrm{ng} / \mathrm{mg}$ ) in large excess of C subunit (52 ng/mg). Studies of PKA subunit degradation rates [61, 62] indicate that it is unlikely differences in measured $\mathrm{R}$ and $\mathrm{C}$ subunit concentrations have arisen from $\mathrm{C}$ subunit degradation during sample preparation in these studies. Furthermore, 2p-FLIM measurements of $\mathrm{C}$ subunit occupation of RII $\beta$ in rat organotypic slices are consistent with high concentrations of $\mathrm{R}$ subunit in molar excess of $\mathrm{C}$ subunits [49].

It is challenging to accurately predict free $\mathrm{C}$ subunit lifetimes as the rate of $\mathrm{C}$ subunit binding to $\mathrm{C}$ subunit-free $\mathrm{R}$ subunits is reduced by RII phosphorylation ( $\sim 50$-fold [43] to $3.8 \times 10^{4} \mathrm{M}^{-1} \mathrm{~s}^{-1}$ for RII $\beta$ ), and potentially also by occupation of both CNB domains by cAMP ([55] - cAMP mostly exerts its effects by increasing $\mathrm{C}$ subunit release rate). Furthermore, different studies have yielded inconsistent numbers for $\mathrm{R}$ and $\mathrm{C}$ subunit association and dissociation rates $[44,63,64])$. For a very approximate intermediate figure, consider a cell containing $2 \mu \mathrm{M}$ cAMP-free phosphorylated RII (pRII) subunits in large excess of $\mathrm{C}$ subunits. $\mathrm{C}$ subunits in this cell would be captured by $\mathrm{pRII}$ at a rate of $\sim 3.8 \times 10^{4}$ 
$\mathrm{M}^{-1} \mathrm{~s}^{-1} \times 2 \times 10^{-6} \mathrm{M}=0.08 \mathrm{~s}^{-1}$. Taking the inverse gives a mean free $\mathrm{C}$ subunit lifetime of $\sim 13$ s. 2p-FLIM experiments have shown that a physiologically realistic level of $\beta$ adrenergic receptor stimulation in CA1 pyramidal neurons produces a level of $\sim 12 \%$ extra liberated $\mathrm{C}$ subunits that is stable for more than 5 minutes [49], a level that may be in the typical range following physiological stimulations [51]. According to $\mathrm{R}$ subunit concentrations and kinetic parameters for $\mathrm{R}$ and $\mathrm{C}$ association, during stimulations in which only a small fraction of total $\mathrm{C}$ subunits are released at any moment in time, $\mathrm{C}$ subunits are dissociating and re-associating with $\mathrm{R}$ subunits over a much shorter timescale than the total duration of elevated PKA activity. If $\mathrm{R}$ and $\mathrm{C}$ subunits were expressed at similar concentrations, $\mathrm{C}$ subunit recapture would occur very slowly during cAMP impulses that release only a small fraction of $\mathrm{C}$ subunits at any moment in time, since most $\mathrm{R}$ subunits would be occupied by $\mathrm{C}$ subunits and unavailable for buffering. This may partly explain why $\mathrm{R}: \mathrm{C}$ ratios are highly skewed towards $\mathrm{R}$ subunits $[50,60]$.

The molar abundance of PKA R subunits calls for reconsideration of the textbook idea that latent PKA activity is distributed in tetrameric holoenzymes. C subunits could conceivably partition mostly into $2 \mathrm{R}-1 \mathrm{C}$ trimers according to the concentrations measured in, e.g., HEK293T cell extracts [50]. A key determinant of tetramer versus trimer partitioning will be the degree of cooperativity of $\mathrm{C}$ to $\mathrm{R}$ subunit binding. Tetrameric structures of RI $\alpha-\mathrm{C} \beta$, RI $\beta-C \beta$ and RII $\beta-C \beta[10]$ show extensive trans-heterodimer contacts so highly cooperative $\mathrm{R}-\mathrm{C}$ binding that would favour tetramer formation appears to be possible. In addition, with molar excesses of $\mathrm{R}$ to $\mathrm{C}$ subunits, there is the potential for uneven distribution of $\mathrm{C}$ subunits between different groups of cellular R subunits. For example, sustained local differences in cAMP concentration or pRII phosphatase activity could drive accumulation of $\mathrm{C}$ subunits at specific sub-cellular regions. In summary, high $\mathrm{R}$ subunit concentrations and skewed $\mathrm{R}: \mathrm{C}$ ratios will support rapid recapture of released $\mathrm{C}$ subunits in cells, and the control of $\mathrm{C}$ subunit distribution between cellular $\mathrm{R}$ subunits merits further investigation. 


\section{Control of C subunit - inhibitor sequence interactions by phosphorylation, metal ions \& ATP}

The IS of RII subunits contains a serine (alanine in RI) that is phosphorylated upon association with the $\mathrm{C}$ subunit dependent on ATP and divalent metal ions. Studies with bovine PKA in the 1970s discovered that $\mathrm{C}$ subunits re-associate more than five times more quickly to the dephosphorylated form of RII [65]. More recently, precise on and off rates for $\mathrm{C}$ subunit association to RII and $\mathrm{pRII} \beta$ were determined by surface plasmon resonance (SPR) [43]. In the presence of $\mathrm{Mg} / \mathrm{ATP}$, the on rate for $\mathrm{C}$ subunit binding is $~ 50$ times faster when RII is not phosphorylated (RII $\beta: C, \mathrm{k}_{\mathrm{on}}=2.1 \times 10^{6}, \mathrm{~K}_{\mathrm{d}}=0.14 \mathrm{nM} ; \mathrm{pRII} \beta: \mathrm{C}, \mathrm{k}_{\mathrm{on}}$ $\left.=3.8 \times 10^{4}, \mathrm{~K}_{\mathrm{d}}=7 \mathrm{nM}\right)$. RII phosphorylation precedes activation by cAMP, and is thought to regulate activity termination [52]. Kinetic modeling shows that, in theory, rapid pRII dephosphorylation is a potent mechanism for suppressing PKA activity [66]. However, the field awaits concrete examples of phosphatase-mediated suppression of PKA activity through RII dephosphorylation. Remarkably, an analogous site has been identified in RI $\alpha$, although in this case the site is phosphorylated by a different kinase - cGMP-dependent protein kinase [67].

Metal ions play an important role in dictating interactions in the $\mathrm{C}$ subunit active site. For type II PKA, SPR measurements of $\mathrm{C}$ subunit release from pRII $\beta$ induced by $100 \mathrm{nM}$ cAMP show that whereas $\mathrm{Mg}^{2+} / \mathrm{ATP}$ supports rapid and complete dissociation, conducting the same experiment with $\mathrm{Ca}^{2+} / \mathrm{ATP}$ leads to only $\sim 50 \% \mathrm{pRII} \beta-\mathrm{C}$ dissociation after several minutes [43]. Experiments with a model substrate show that while $\mathrm{Mg}^{2+}$ ions are highly efficient for turnover catalysis [68] in that they support stable substrate binding and rapid product release, $\mathrm{Ca}^{2+}$ ions trap enzyme-product complexes [69]. PKA is anchored in proximity to several ion channels that conduct $\mathrm{Ca}^{2+}$ ions including L-type $\mathrm{Ca}^{2+}$ channels [70], and it is plausible that high local concentrations of $\mathrm{Ca}^{2+}$ at the mouths of these channels could enable $\mathrm{Ca}^{2+}$-cAMP crosstalk in a novel way by trapping $\mathrm{C}$ subunitsubstrate/pRII complexes. Conversely, $\mathrm{Mg}^{2+}$ and ATP are essential for high affinity binding of $\mathrm{C}$ subunits to both RI subunits and protein kinase inhibitor peptide (PKI) [63] with the second low-affinity metal binding site in the $\mathrm{C}$ subunit playing an essential role in 
these interactions [71]. Since the IS in RI is a pseudosubstrate, ATP acts as an orthosteric inhibitor that supports RI-C complex formation rather than as a substrate for phosphate transfer as in RII holoenzymes [11]. The dependence of RI-C interactions on ATP suggests that type I PKA activity may rise in response to low energy levels [11].

\section{Membrane insertion of myristylated catalytic subunits}

The range of action of liberated $\mathrm{C}$ subunits also depends on their diffusion rate, and membrane insertion of myristylated $\mathrm{C}$ subunits is emerging as an important mechanism for controlling $\mathrm{C}$ subunit diffusion. The $\mathrm{N}$-termini of most mammalian $\mathrm{C}$ subunits are myristylated, with the exception of two low abundance splice variants of $C \beta$ [72] and a splice variant of $\mathrm{C} \alpha$ that is expressed in spermatocytes [73]. Myristylation confers thermal stability to the $\mathrm{C}$ subunit [74]. NMR experiments show that the $\mathrm{C}$ subunit exists in equilibrium between 'myr-in' and 'myr-out' states [75]. In the myr-in conformation, the myristyl group is buried in a deep pocket on the kinase domain, forming an attachment point for the first $\sim 40$ amino acids of the $C$ subunit [76]. Association with RII subunits and/or phosphorylation at Ser10 in the C subunit A-helix shifts the equilibrium to the myrout conformation in which the myristyl group projects away from the $C$ subunit $[75,77]$ in the general direction of the RII subunit D/D domain [50]. By stabilizing the myr-out conformation of the $\mathrm{C}$ subunit [78], RII - but not RI - subunits markedly increase $\mathrm{C}$ subunit binding to liposomes [77] and bicelles [75].

Fluorescence decay experiments with wild type and myristylation-deficient (G2A) C subunits fused to photoactivatable GFP in neurons support a key role for myristylation in reducing C subunit motility [49]. Tillo and co-workers found that the time constant for wild-type $C$ subunit upon norepinephrine stimulation $(\tau=2.11 \mathrm{~s})$ is significantly longer than for the myristylation-deficient mutant G2A ( $\tau=0.73 \mathrm{~s})$ [49]. Several genetic studies support an increased role for RI compared to RII in regulating nuclear C subunit entry and gene regulation (Figure 2A). For example, the tissue-extinguisher locus - a dominant

regulator of transcription - was found to encode RI $\alpha$ subunits [79, 80]. Cre-dependent 
luciferase expression in HEK293 cells is more sensitive to RI $\alpha$ than RII $\alpha$ over-expression [7]. Furthermore, Ilouz and co-workers [8] recently found that RI $\beta$ but not RII $\beta$ contributes to PKA-dependent cAMP-response element binding protein phosphorylation. If $\mathrm{C}$ subunits released from RII typically associate with cellular membranes (Figure 2B), this may partly explain why type II PKA is less important than type I for releasing C subunits that enter the nucleus.

\section{Perspectives}

- Phosphorylation by PKA is a critical step in many biological processes, and imbalances in the expression or activity of PKA subunits [81-83] and disruptions in PKA anchoring [84] are pathological. A major outstanding issue is to understand how the activity of PKA C subunits is spatially and temporally controlled in cells. Obtaining a detailed understanding of the molecular basis of PKA targeting may reveal novel strategies for pharmacological targeting of cAMP signalling.

- PKA activity is controlled in part by association with AKAP proteins, but anchoring does not directly account for restraint of $\mathrm{C}$ subunits after they are released following cAMP stimulation. Physiological agonists lead to dissociation of $\mathrm{C}$ subunits from PKA holoenzymes in cells, and there is no definitive data supporting a major role for phosphorylation by cAMP-activated intact type II PKA holoenzymes. R subunits are highly abundant and in large molar excess of $\mathrm{C}$ subunits, which will ensure rapid recapture of liberated $\mathrm{C}$ subunits. Membrane insertion of myristylated C subunit released from type II PKA holoenzymes reduces the rate of $\mathrm{C}$ subunit diffusion, and RII subunit dephosphorylation increases the rate of $\mathrm{C}$ subunit recapture.

- The possibility that $\mathrm{C}$ subunits preferentially distribute to certain $\mathrm{R}$ subunits isoforms or to specific AKAP-RII complexes merits investigation. Controlling RII dephosphorylation state, and $\mathrm{Ca}^{2+}$ trapping of $\mathrm{C}-\mathrm{R} /$ substrate complexes are 
potential mechanisms for regulating PKA activity in cells but the biological significance of these mechanisms is yet to be established. Structural information concerning PKA anchoring is limited to AKAP peptides bound to D/D domains [23, $24,85,86]$, isolated AKAP domains [87], and low-resolution structures of fulllength AKAP-PKA complexes [51]. Future structural studies may examine interactions to sites on PKA holoenzymes besides the D/D domain including the variable loop regions that span the $\mathrm{D} / \mathrm{D}$ and inhibitor sequences in each regulatory subunit. For example, PDE8 associates with the CNB domains of RIalpha to enhance the rate of cAMP hydrolysis via a channeling mechanism [88]. More accurate values for PKA subunit concentrations [50], $\mathrm{C}$ association and dissociation rates [43], and cellular cAMP concentrations [89] have been established within the last five years. The field would benefit from a renewed focus on kinetic modeling of PKA signalling dynamics $[52,90,91]$ to accurately calculate, e.g., mean $\mathrm{C}$ subunit lifetimes under different cellular conditions, taking advantage of these new kinetic parameters. Models may factor in complications including the ability of substrates to increase dissociation of C subunits from RI and PKI but not RII [39, 44, 92], fluctuations in PKA subunit levels controlled by ubiquitination [93], and C subunit interactions with PKI which also occur in the nucleus [94]. 


\title{
Author Contribution
}

M.G.G. wrote the paper.

\section{Funding}

M.G.G. is a Wellcome Trust and Royal Society Sir Henry Dale fellow (104194/Z/14/Z), and receives support from the BBSRC (BB/N015274/1).

\section{Competing Interests}

The Author declares that there are no competing interests associated with this manuscript.

\begin{abstract}
Abbreviations
2p-FLIM, two-photon fluorescence lifetime imaging microscopy; AKAP, A-kinase anchoring protein; $\mathrm{C}$, catalytic; ${ }^{\mathrm{CF}} \mathrm{C}$, carboxyfluorescein-C; $\mathrm{CNB}$ cyclic nucleotide binding; D/D, dimerisation and docking domain; HEK, human embryonic kidney; IS, inhibitor sequence; PKA, protein kinase A; pRII, phosphorylated RII; RI/RII, regulatory type I/II; SPR, surface plamon resonance.
\end{abstract}




\section{Table 1}

\begin{tabular}{|c|c|}
\hline Observations supporting activation through dissociation & Observations supporting non-dissociative activation \\
\hline \multicolumn{2}{|l|}{ In vitro experiments } \\
\hline $\begin{array}{l}\text { Separation using cation exchange resin: for both type I and II PKA purified from } \\
\text { rabbit skeletal muscle, regulatory subunits can be separated from the catalytic } \\
\text { subunits by incubation with CM sephadex C-50 in the presence of } 100 \mu \mathrm{M} \\
\text { cAMP (the regulatory subunits flow through), e.g., [32] }]^{\mathrm{a}} \text {. }\end{array}$ & $\begin{array}{l}\text { Fluorescence measurements with carboxyfluorescein-labelled } \mathrm{C} \text { subunit }\left({ }^{\mathrm{CF}} \mathrm{C}\right) \text { : } \\
\text { residual FRET recorded between }{ }^{\mathrm{CF}} \mathrm{C} \text { and texas red-labelled RII at very high }(100 \mu \mathrm{M}) \\
\text { cAMP concentrations [42]. Adding } 50 \mu \mathrm{M} \text { cAMP to RII- }{ }^{\mathrm{CF}} \mathrm{C} \text { holoenzymes did not } \\
\text { significantly reduce the rotational mobility of }{ }^{\mathrm{CF}} \mathrm{C} \text { according to time-resolved } \\
\text { emission anisotropy measurements [41], indicating that cAMP had not triggered C } \\
\text { subunit release }{ }^{\mathrm{d}} \text {. }\end{array}$ \\
\hline $\begin{array}{l}\text { Affinity to casein-sepharose column: experiments with PKA purified from } \\
\text { skeletal muscle PKA (mixture of type I and II) show that cAMP releases } \\
\text { majority of C subunits enabling their capture with casein-sepharose [33]. }\end{array}$ & $\begin{array}{l}\text { Native MS of purified RII-C-AKAP79 (297-427) complex [51]: RII-C-2cAMP and } \\
\text { RII-C-4cAMP sub-complexes detected in the gas phase }{ }^{\mathrm{e}} \text {. }\end{array}$ \\
\hline \multicolumn{2}{|l|}{$\begin{array}{l}\text { Size-exclusion chromatography: } 1 \mu \mathrm{M} \text { cAMP triggers separation of } \mathrm{R} \text { and } \mathrm{C} \\
\text { subunits during size-exclusion chromatography with sephadex G-200 column } \\
\text { for both type I [36] and type II PKA }[36,37] .\end{array}$} \\
\hline \multicolumn{2}{|l|}{$\begin{array}{l}\text { Sucrose gradient ultracentrifugation: } \mathrm{R} \text { and } \mathrm{C} \text { subunits for both type I and II PKA } \\
\text { are separated by sucrose gradient ultracentrifugation when } 10 \mu \mathrm{M} \text { cAMP is } \\
\text { included [38]. }\end{array}$} \\
\hline \multicolumn{2}{|l|}{$\begin{array}{l}\text { Affinity to cAMP agarose: incubation of either type I [34] or II [35] PKA } \\
\text { holoenzymes with cAMP agarose leads to recovery of only the R subunits. }\end{array}$} \\
\hline \multicolumn{2}{|l|}{$\begin{array}{l}\text { Small-angle } \mathrm{x} \text {-ray scattering: pair-distance distribution functions show decreases } \\
\text { in radius when } 1 \mathrm{mM} \text { cAMP is added to either type I } \alpha \text { or type II } \beta \text { PKA } \\
\text { holoenzymes [39], indicative of } \mathrm{C} \text { subunit release. }\end{array}$} \\
\hline $\begin{array}{l}\text { AlphaScreen assay: Signal indicating association of GST-RI and biotinylated C } \\
\text { subunit reduced to background levels at high cAMP concentration [40]. }\end{array}$ & \\
\hline
\end{tabular}




\begin{tabular}{|c|c|}
\hline \multicolumn{2}{|l|}{ In cultured cells } \\
\hline $\begin{array}{l}\text { UV crosslinking of } \mathrm{C} \text { subunits to both RI and RII in HEK cells is reduced by } \\
>70 \% \text { when cells are illuminated immediately following stimulation with } 1 \mu \mathrm{M} \\
\text { isoproterenol }[50]^{\mathrm{c}} \text {. }\end{array}$ & $\begin{array}{l}\text { Immunoprecipitation (IP) experiments with HEK cells: Co-IP of C subunits with } \\
\text { AKAP79-RII }[51,53] \text { and AKAP18-RII [51] is not affected by stimulation with } 1 \mu \mathrm{M} \\
\text { isoproterenol }^{\mathrm{f}} \text {. }\end{array}$ \\
\hline \multicolumn{2}{|l|}{$\begin{array}{l}\text { FRET between micro-injected fluorescently-labelled PKA subunits: FRET } \\
\text { between C } \alpha \text {-fluorescein and RI } \alpha \text {-rhodamine decreased by cAMP in vitro, and } \\
\text { by, e.g., } 100 \mathrm{nM} \text { isoproterenol in micro-injected smooth muscle and fibroflast } \\
\text { cell lines [45]. Experiments with same micro-injected subunits in Aplysia } \\
\text { sensory neurons show that FRET changes are proportional to the extent of C } \\
\text { subunit translocation into the nucleus [46]. }\end{array}$} \\
\hline \multicolumn{2}{|l|}{$\begin{array}{l}\text { FRET between PKA subunits fused to GFP variants: Isoproterenol triggers } \\
\text { reduction in FRET between RII-EBFP and C-GFP(E65T) and C and } \\
\text { accumulation of nuclear C subunits in transfected COS-7 cells [47]. } \\
\text { Norepinephrine triggers reduced FRET between same reporters in neonatal rat } \\
\text { cardiac myocytes [48]. }\end{array}$} \\
\hline \multicolumn{2}{|l|}{$\begin{array}{l}\text { 2p-FLIM: Experiments using } \mathrm{C} \text {-terminally tagged } \mathrm{C} \text { and RII subunits in } \\
\text { hippocampal primary neurons show that } 20 \mu \mathrm{M} \text { norepinephrine triggers a } 12 \% \\
\text { reduction in the fraction of } \mathrm{C} \text { subunits associated with RII, with forskolin/IBMX } \\
\text { stimulation generating a further } 70 \% \text { reduction [49]. }\end{array}$} \\
\hline \multicolumn{2}{|l|}{$\begin{array}{l}\text { Proximity ligation assay: HEK } 293 \text { cells exhibit approximately half as many } \\
\text { puncta indicating intact PKA holoenyzmes when cells are stimulated with } \\
\text { isoproterenol and rolipram [51]. }\end{array}$} \\
\hline $\begin{array}{l}\text { Bioluminescence resonance energy transfer (BRET) recordings: BRET is } \\
\text { reduced between GFP-tagged } \mathrm{C} \alpha \text { and all four R subunit isoforms when HEK293 } \\
\text { cells are stimulated with forskolin/IBMX [52]. BRET between GFP-C and RII } \alpha- \\
\text { luciferase in COS-7 cells is reduced to baseline levels upon addition of } 8 \mathrm{Br}- \\
\text { cAMP-AM [40]. }\end{array}$ & \\
\hline
\end{tabular}




\section{Figure \& Table Legends}

Table 1. Observations for and against CAMP-induced dissociation of $\mathrm{C}$ subunits. The table refers to the following footnotes: (a) Binding to exchanger resin performed at $\mathrm{pH}$ 6.7. (b) For both holoenzymes, $1 \mathrm{mM}$ cAMP reduces to $\sim 40 \%$ intact holoenzymes. I $\alpha$ but not II $\beta$ holoenzymes can be completely dissociated by additionally adding kemptide substrate peptide. (c) The spacer arm in NHS-Diazirine is $3.9 \AA$ long, so a structural rearrangement in which the $\mathrm{C}$ subunits are retained might reduce crosslinking efficiency between $\mathrm{R}$ and C subunits. (d) C subunits were non-specifically labelled with amine-reactive probes that may have blocked the effect of autophosphorylation on RII-C binding affinity, and prevented complete dissociation as discussed in [44]. (e) In most chemical species detected by the spectrometer that contained both RII and C subunits, fewer than 2cAMP were present per RII subunit. (f) Co-IP performed after lysing cells and diluting in lysis buffer. UV crosslinking experiments suggest that RII-C complexes reform following cell lysis after isoproterenol stimulation [50].

Figure 1. Primary pathway for $\mathbf{C}$ subunit dissociation. (A) Prior to cAMP binding, $R$ subunits (blue) sequester C subunits (green) through an extensive interface involving both CNB domains, and through docking of the IS in the substrate binding groove of the C subunit. (B) Occupation of the CNB domains by two molecules of cAMP (yellow) leads to kinking of a helix that bridges the two domains, and thereby breaks the interface between the CNB domains and the $\mathrm{C}$ subunit. (C) Subsequent dissociation of the IS disinhibits the $\mathrm{C}$ subunit and is concomitant with $\mathrm{C}$ subunit dissociation. (D) Fusing RII and C subunits generates a synthetic version of PKA that may be activated by cAMP without $\mathrm{C}$ subunit dissociation [51], which has been put forward as evidence that cAMP activates PKA via intact holoenzymes. However, this is not a realistic model of activation without dissociation since in the synthetic fusion protein cAMP may trigger dissociation of both the CNB domain and IS interfaces without full $\mathrm{C}$ subunit release due to the covalent linker connecting the RII and C subunits. Structural representations are taken from crystal structures of truncated RII $\beta$ in complex with either cAMP [57] or myristylated C $\alpha$ [78]. For the sake of clarity, the scheme is simplified to interactions involving single RII 
protomers, and the RII D/D domain is not shown. In tetrameric PKA holoenzymes, interactions between the two R-C heterodimers support cooperative activation by cAMP.

Figure 2. C subunit myristyl group conformations in type I and II PKA. (A) In type I PKA, the 'myr-in' conformation of the C subunit (green) is stabilised, in which the myristyl group (orange) packs against the kinase domain core. Upon release by cAMP (yellow), movement of the $\mathrm{C}$ subunit is not restricted to cellular membranes, which may partly explain why type I PKA is more important for nuclear PKA activity. (B) In complex with RII subunits, the myr-out conformation is stabilised. Non-dissociated type II holoenzymes can associate with membranes in the absence of anchoring, with membrane-tethered AKAPs likely supporting this behaviour. Diffusion of $\mathrm{C}$ subunits released from these holoenzymes by cAMP is limited due to insertion of myristyl at the $\mathrm{N}$-terminus of the $\mathrm{C}$ subunit into the intracellular face of membranes including the cell membrane. 


\section{References}

1 Nichols, C. B., Rossow, C. F., Navedo, M. F., Westenbroek, R. E., Catterall, W. A., Santana, L. F. and McKnight, G. S. (2010) Sympathetic stimulation of adult cardiomyocytes requires association of AKAP5 with a subpopulation of L-type calcium channels. Circ Res. 107, 747-756

2 Liao, Z., Lockhead, D., Larson, E. D. and Proenza, C. (2010) Phosphorylation and modulation of hyperpolarization-activated HCN4 channels by protein kinase A in the mouse sinoatrial node. J Gen Physiol. 136, 247-258

3 Kaihara, K. A., Dickson, L. M., Jacobson, D. A., Tamarina, N., Roe, M. W., Philipson, L. H. and Wicksteed, B. (2013) beta-Cell-specific protein kinase A activation enhances the efficiency of glucose control by increasing acute-phase insulin secretion. Diabetes. 62, 1527-1536

4 Yang, H. and Yang, L. (2016) Targeting cAMP/PKA pathway for glycemic control and type 2 diabetes therapy. J Mol Endocrinol. 57, R93-R108 5 Gold, M. G., Reichow, S. L., O'Neill, S. E., Weisbrod, C. R., Langeberg, L. K., Bruce, J. E., Gonen, T. and Scott, J. D. (2012) AKAP2 anchors PKA with aquaporin-0 to support ocular lens transparency. EMBO molecular medicine. 4, 15-26

6 Kandel, E. R. (2012) The molecular biology of memory: cAMP, PKA, CRE, CREB-1, CREB-2, and CPEB. Mol Brain. 5, 14

7 Kopperud, R., Christensen, A. E., Kjarland, E., Viste, K., Kleivdal, H. and Doskeland, S. O. (2002) Formation of inactive cAMP-saturated holoenzyme of cAMP- 
dependent protein kinase under physiological conditions. The Journal of biological chemistry. 277, 13443-13448

8 Ilouz, R., Lev-Ram, V., Bushong, E. A., Stiles, T. L., Friedmann-Morvinski, D., Douglas, C., Goldberg, J. L., Ellisman, M. H. and Taylor, S. S. (2017) Isoform-specific subcellular localization and function of protein kinase A identified by mosaic imaging of mouse brain. Elife. 6

9 Corbin, J. D., Sugden, P. H., Lincoln, T. M. and Keely, S. L. (1977)

Compartmentalization of adenosine $3^{\prime}: 5^{\prime}$-monophosphate and adenosine $3^{\prime}: 5^{\prime}-$

monophosphate-dependent protein kinase in heart tissue. The Journal of biological chemistry. 252, 3854-3861

10 Taylor, S. S., Ilouz, R., Zhang, P. and Kornev, A. P. (2012) Assembly of allosteric macromolecular switches: lessons from PKA. Nat Rev Mol Cell Biol. 13, 646-658 11 Lu, T. W., Wu, J., Aoto, P. C., Weng, J. H., Ahuja, L. G., Sun, N., Cheng, C. Y., Zhang, P. and Taylor, S. S. (2019) Two PKA RIalpha holoenzyme states define ATP as an isoform-specific orthosteric inhibitor that competes with the allosteric activator, cAMP. Proceedings of the National Academy of Sciences of the United States of America. 116, 16347-16356

12 Cummings, D. E., Brandon, E. P., Planas, J. V., Motamed, K., Idzerda, R. L. and McKnight, G. S. (1996) Genetically lean mice result from targeted disruption of the RII beta subunit of protein kinase A. Nature. 382, 622-626

13 Schreyer, S. A., Cummings, D. E., McKnight, G. S. and LeBoeuf, R. C. (2001) Mutation of the RIIbeta subunit of protein kinase A prevents diet-induced insulin resistance and dyslipidemia in mice. Diabetes. 50, 2555-2562 
14 Amieux, P. S., Cummings, D. E., Motamed, K., Brandon, E. P., Wailes, L. A., Le, K., Idzerda, R. L. and McKnight, G. S. (1997) Compensatory regulation of RIalpha protein levels in protein kinase A mutant mice. The Journal of biological chemistry. 272, 3993-3998

15 Soberg, K., Moen, L. V., Skalhegg, B. S. and Laerdahl, J. K. (2017) Evolution of the cAMP-dependent protein kinase (PKA) catalytic subunit isoforms. PLoS One. 12, $\mathrm{e} 0181091$

16 Surdo, N. C., Berrera, M., Koschinski, A., Brescia, M., Machado, M. R., Carr, C., Wright, P., Gorelik, J., Morotti, S., Grandi, E., Bers, D. M., Pantano, S. and Zaccolo, M. (2017) FRET biosensor uncovers cAMP nano-domains at beta-adrenergic targets that dictate precise tuning of cardiac contractility. Nat Commun. 8, 15031

17 Bers, D. M., Xiang, Y. K. and Zaccolo, M. (2019) Whole-Cell cAMP and PKA Activity are Epiphenomena, Nanodomain Signaling Matters. Physiology (Bethesda). 34, 240-249

18 Depry, C., Allen, M. D. and Zhang, J. (2011) Visualization of PKA activity in plasma membrane microdomains. Molecular bioSystems. 7, 52-58

19 Greenwald, E. C., Mehta, S. and Zhang, J. (2018) Genetically Encoded

Fluorescent Biosensors Illuminate the Spatiotemporal Regulation of Signaling Networks. Chem Rev. 118, 11707-11794

20 Keely, S. L. (1979) Prostaglandin E1 activation of heart cAMP-dependent protein kinase: apparent dissociation of protein kinase activation from increases in phosphorylase activity and contractile force. Molecular pharmacology. 15, 235-245 
21 Hayes, J. S., Brunton, L. L. and Mayer, S. E. (1980) Selective activation of particulate cAMP-dependent protein kinase by isoproterenol and prostaglandin E1. The Journal of biological chemistry. 255, 5113-5119

22 Vallee, R. B., DiBartolomeis, M. J. and Theurkauf, W. E. (1981) A protein kinase bound to the projection portion of MAP 2 (microtubule-associated protein 2). J Cell Biol. 90, $568-576$

23 Gold, M. G., Lygren, B., Dokurno, P., Hoshi, N., McConnachie, G., Tasken, K., Carlson, C. R., Scott, J. D. and Barford, D. (2006) Molecular basis of AKAP specificity for PKA regulatory subunits. Mol Cell. 24, 383-395

24 Kinderman, F. S., Kim, C., von Daake, S., Ma, Y., Pham, B. Q., Spraggon, G., Xuong, N. H., Jennings, P. A. and Taylor, S. S. (2006) A dynamic mechanism for AKAP binding to RII isoforms of cAMP-dependent protein kinase. Mol Cell. 24, 397-408 25 Langeberg, L. K. and Scott, J. D. (2015) Signalling scaffolds and local organization of cellular behaviour. Nat Rev Mol Cell Biol. 16, 232-244

26 Halls, M. L. and Cooper, D. M. F. (2017) Adenylyl cyclase signalling complexes - Pharmacological challenges and opportunities. Pharmacol Ther. 172, 171-180

27 Dodge, K. L., Khouangsathiene, S., Kapiloff, M. S., Mouton, R., Hill, E. V., Houslay, M. D., Langeberg, L. K. and Scott, J. D. (2001) mAKAP assembles a protein kinase A/PDE4 phosphodiesterase cAMP signaling module. Embo J. 20, 1921-1930 28 Maurice, D. H., Ke, H., Ahmad, F., Wang, Y., Chung, J. and Manganiello, V. C. (2014) Advances in targeting cyclic nucleotide phosphodiesterases. Nat Rev Drug Discov. 13, 290-314 
29 Lefkimmiatis, K. and Zaccolo, M. (2014) cAMP signaling in subcellular compartments. Pharmacol Ther. 143, 295-304

30 McCormick, K. and Baillie, G. S. (2014) Compartmentalisation of second messenger signalling pathways. Current opinion in genetics \& development. 27, 20-25

31 Rall, T. W. (1975) Opening Remarks. Adv Cyclic Nucleotide Res. 5, 1-2

32 Beavo, J. A., Bechtel, P. J. and Krebs, E. G. (1974) Preparation of homogeneous cyclic AMP-dependent protein kinase(s) and its subunits from rabbit skeletal muscle. Methods Enzymol. 38, 299-308

33 Reimann, E. M., Brostrom, C. O., Corbin, J. D., King, C. A. and Krebs, E. G. (1971) Separation of regulatory and catalytic subunits of the cyclic 3',5'-adenosine monophosphate-dependent protein kinase(s) of rabbit skeletal muscle. Biochem Biophys Res Commun. 42, 187-194

34 Dills, W. L., Jr., Beavo, J. A., Bechtel, P. J. and Krebs, E. G. (1975) Purification of rabbit skeletal muscle protein kinase regulatory subunit using cyclic adenosine-3':5'monophosphate affinity chromatography. Biochem Biophys Res Commun. 62, 70-77 35 Corbin, J. D., Sugden, P. H., West, L., Flockhart, D. A., Lincoln, T. M. and McCarthy, D. (1978) Studies on the properties and mode of action of the purified regulatory subunit of bovine heart adenosine 3':5'-monophosphate-dependent protein kinase. The Journal of biological chemistry. 253, 3997-4003

36 Erlichman, J., Hirsch, A. H. and Rosen, O. M. (1971) Interconversion of cyclic nucleotide-activated and cyclic nucleotide-independent forms of a protein kinase from beef heart. Proceedings of the National Academy of Sciences of the United States of America. 68, 731-735 
37 Kumon, A., Nishiyama, K., Yamamura, H. and Nishizuka, Y. (1972) Multiplicity of adenosine 3',5'-monophosphate-dependent protein kinases from rat liver and mode of action of nucleoside 3',5'-monophosphate. The Journal of biological chemistry. 247, $3726-3735$

38 Hofmann, F., Beavo, J. A., Bechtel, P. J. and Krebs, E. G. (1975) Comparison of adenosine $3^{\prime}: 5^{\prime}$-monophosphate-dependent protein kinases from rabbit skeletal and bovine heart muscle. The Journal of biological chemistry. 250, 7795-7801

39 Vigil, D., Blumenthal, D. K., Brown, S., Taylor, S. S. and Trewhella, J. (2004)

Differential effects of substrate on type I and type II PKA holoenzyme dissociation.

Biochemistry. 43, 5629-5636

40 Moll, D., Prinz, A., Gesellchen, F., Drewianka, S., Zimmermann, B. and Herberg, F. W. (2006) Biomolecular interaction analysis in functional proteomics. J Neural Transm (Vienna). 113, 1015-1032

41 Yang, S., Fletcher, W. H. and Johnson, D. A. (1995) Regulation of cAMPdependent protein kinase: enzyme activation without dissociation. Biochemistry. 34, $6267-6271$

42 Johnson, D. A., Leathers, V. L., Martinez, A. M., Walsh, D. A. and Fletcher, W. H. (1993) Fluorescence resonance energy transfer within a heterochromatic cAMPdependent protein kinase holoenzyme under equilibrium conditions: new insights into the conformational changes that result in cAMP-dependent activation. Biochemistry. 32 , 6402-6410 
43 Zhang, P., Knape, M. J., Ahuja, L. G., Keshwani, M. M., King, C. C., Sastri, M., Herberg, F. W. and Taylor, S. S. (2015) Single Turnover Autophosphorylation Cycle of the PKA RIIbeta Holoenzyme. PLoS Biol. 13, e1002192

44 Anand, G., Taylor, S. S. and Johnson, D. A. (2007) Cyclic-AMP and pseudosubstrate effects on type-I A-kinase regulatory and catalytic subunit binding kinetics. Biochemistry. 46, 9283-9291

45 Adams, S. R., Harootunian, A. T., Buechler, Y. J., Taylor, S. S. and Tsien, R. Y. (1991) Fluorescence ratio imaging of cyclic AMP in single cells. Nature. 349, 694-697

46 Bacskai, B. J., Hochner, B., Mahaut-Smith, M., Adams, S. R., Kaang, B. K., Kandel, E. R. and Tsien, R. Y. (1993) Spatially resolved dynamics of cAMP and protein kinase A subunits in Aplysia sensory neurons. Science. 260, 222-226

47 Zaccolo, M., De Giorgi, F., Cho, C. Y., Feng, L., Knapp, T., Negulescu, P. A., Taylor, S. S., Tsien, R. Y. and Pozzan, T. (2000) A genetically encoded, fluorescent indicator for cyclic AMP in living cells. Nat Cell Biol. 2, 25-29

48 Zaccolo, M. and Pozzan, T. (2002) Discrete microdomains with high concentration of cAMP in stimulated rat neonatal cardiac myocytes. Science. 295, 17111715

49 Tillo, S. E., Xiong, W. H., Takahashi, M., Miao, S., Andrade, A. L., Fortin, D. A., Yang, G., Qin, M., Smoody, B. F., Stork, P. J. S. and Zhong, H. (2017) Liberated PKA Catalytic Subunits Associate with the Membrane via Myristoylation to Preferentially Phosphorylate Membrane Substrates. Cell reports. 19, 617-629

50 Walker-Gray, R., Stengel, F. and Gold, M. G. (2017) Mechanisms for restraining cAMP-dependent protein kinase revealed by subunit quantitation and cross-linking 
approaches. Proceedings of the National Academy of Sciences of the United States of America. 114, 10414-10419

51 Smith, F. D., Esseltine, J. L., Nygren, P. J., Veesler, D., Byrne, D. P., Vonderach, M., Strashnov, I., Eyers, C. E., Eyers, P. A., Langeberg, L. K. and Scott, J. D. (2017) Local protein kinase A action proceeds through intact holoenzymes. Science. 356, 12881293

52 Isensee, J., Kaufholz, M., Knape, M. J., Hasenauer, J., Hammerich, H., Gonczarowska-Jorge, H., Zahedi, R. P., Schwede, F., Herberg, F. W. and Hucho, T. (2018) PKA-RII subunit phosphorylation precedes activation by cAMP and regulates activity termination. J Cell Biol. 217, 2167-2184

53 Smith, F. D., Reichow, S. L., Esseltine, J. L., Shi, D., Langeberg, L. K., Scott, J. D. and Gonen, T. (2013) Intrinsic disorder within an AKAP-protein kinase A complex guides local substrate phosphorylation. Elife. 2, e01319

54 Builder, S. E., Beavo, J. A. and Krebs, E. G. (1980) The mechanism of activation of bovine skeletal muscle protein kinase by adenosine 3':5'-monophosphate. The Journal of biological chemistry. 255, 3514-3519

55 Tsuzuki, J. and Kiger, J. A., Jr. (1978) A kinetic study of cyclic adenosine 3':5'monophosphate binding and mode of activation of protein kinase from Drosophila melanogaster embryos. Biochemistry. 17, 2961-2970

56 Su, Y., Dostmann, W. R., Herberg, F. W., Durick, K., Xuong, N. H., Ten Eyck, L., Taylor, S. S. and Varughese, K. I. (1995) Regulatory subunit of protein kinase A: structure of deletion mutant with cAMP binding domains. Science. 269, 807-813 
57 Diller, T. C., Madhusudan, Xuong, N. H. and Taylor, S. S. (2001) Molecular basis for regulatory subunit diversity in cAMP-dependent protein kinase: crystal structure of the type II beta regulatory subunit. Structure. 9, 73-82

58 England, J. P., Hao, Y., Bai, L., Glick, V., Hodges, H. C., Taylor, S. S. and Maillard, R. A. (2018) Switching of the folding-energy landscape governs the allosteric activation of protein kinase A. Proceedings of the National Academy of Sciences of the United States of America. 115, E7478-E7485

59 Wang, Y. H., Scott, J. D., McKnight, G. S. and Krebs, E. G. (1991) A constitutively active holoenzyme form of the cAMP-dependent protein kinase. Proceedings of the National Academy of Sciences of the United States of America. 88, $2446-2450$

60 Aye, T. T., Scholten, A., Taouatas, N., Varro, A., Van Veen, T. A., Vos, M. A. and Heck, A. J. (2010) Proteome-wide protein concentrations in the human heart. Molecular bioSystems. 6, 1917-1927

61 Boundy, V. A., Chen, J. and Nestler, E. J. (1998) Regulation of cAMP-dependent protein kinase subunit expression in CATH.a and SH-SY5Y cells. J Pharmacol Exp Ther. 286, 1058-1065

62 Lee, S. L. and Steinberg, R. A. (1996) Pathways for degradation of the catalytic subunit of cAMP-dependent protein kinase differ in wild-type and kinase-negative S49 mouse lymphoma cells. The Journal of biological chemistry. 271, 16553-16558 63 Herberg, F. W. and Taylor, S. S. (1993) Physiological inhibitors of the catalytic subunit of cAMP-dependent protein kinase: effect of MgATP on protein-protein interactions. Biochemistry. 32, 14015-14022 
64 Herberg, F. W., Dostmann, W. R., Zorn, M., Davis, S. J. and Taylor, S. S. (1994)

Crosstalk between domains in the regulatory subunit of cAMP-dependent protein kinase: influence of amino terminus on cAMP binding and holoenzyme formation. Biochemistry. 33, $7485-7494$

65 Rangel-Aldao, R. and Rosen, O. M. (1976) Dissociation and reassociation of the phosphorylated and nonphosphorylated forms of adenosine $3^{\prime}: 5^{\prime}$-monophosphatedependent protein kinase from bovine cardiac muscle. The Journal of biological chemistry. 251, 3375-3380

66 Buxbaum, J. D. and Dudai, Y. (1989) A quantitative model for the kinetics of cAMP-dependent protein kinase (type II) activity. Long-term activation of the kinase and its possible relevance to learning and memory. The Journal of biological chemistry. 264, 9344-9351

67 Haushalter, K. J., Casteel, D. E., Raffeiner, A., Stefan, E., Patel, H. H. and Taylor, S. S. (2018) Phosphorylation of protein kinase A (PKA) regulatory subunit RIalpha by protein kinase $\mathrm{G}(\mathrm{PKG})$ primes PKA for catalytic activity in cells. The Journal of biological chemistry. 293, 4411-4421

68 Knape, M. J., Ballez, M., Burghardt, N. C., Zimmermann, B., Bertinetti, D., Kornev, A. P. and Herberg, F. W. (2017) Divalent metal ions control activity and inhibition of protein kinases. Metallomics. 9, 1576-1584

69 Knape, M. J., Ahuja, L. G., Bertinetti, D., Burghardt, N. C., Zimmermann, B., Taylor, S. S. and Herberg, F. W. (2015) Divalent Metal Ions $\mathrm{Mg}(2)(+)$ and $\mathrm{Ca}(2)(+)$ Have Distinct Effects on Protein Kinase A Activity and Regulation. ACS Chem Biol. 10, 2303-2315 
70 Harvey, R. D. and Hell, J. W. (2013) CaV1.2 signaling complexes in the heart. J Mol Cell Cardiol. 58, 143-152

71 Zimmermann, B., Schweinsberg, S., Drewianka, S. and Herberg, F. W. (2008)

Effect of metal ions on high-affinity binding of pseudosubstrate inhibitors to PKA.

Biochem J. 413, 93-101

72 Guthrie, C. R., Skalhegg, B. S. and McKnight, G. S. (1997) Two novel brainspecific splice variants of the murine Cbeta gene of cAMP-dependent protein kinase. The Journal of biological chemistry. 272, 29560-29565

73 Desseyn, J. L., Burton, K. A. and McKnight, G. S. (2000) Expression of a nonmyristylated variant of the catalytic subunit of protein kinase A during male germ-cell development. Proceedings of the National Academy of Sciences of the United States of America. 97, 6433-6438

74 Yonemoto, W., McGlone, M. L. and Taylor, S. S. (1993) N-myristylation of the catalytic subunit of cAMP-dependent protein kinase conveys structural stability. The Journal of biological chemistry. 268, 2348-2352

75 Gaffarogullari, E. C., Masterson, L. R., Metcalfe, E. E., Traaseth, N. J., Balatri, E., Musa, M. M., Mullen, D., Distefano, M. D. and Veglia, G. (2011) A myristoyl/phosphoserine switch controls cAMP-dependent protein kinase association to membranes. Journal of molecular biology. 411, 823-836

76 Zheng, J., Knighton, D. R., Xuong, N. H., Taylor, S. S., Sowadski, J. M. and Ten Eyck, L. F. (1993) Crystal structures of the myristylated catalytic subunit of cAMPdependent protein kinase reveal open and closed conformations. Protein science : a publication of the Protein Society. 2, 1559-1573 
77 Gangal, M., Clifford, T., Deich, J., Cheng, X., Taylor, S. S. and Johnson, D. A. (1999) Mobilization of the A-kinase N-myristate through an isoform-specific intermolecular switch. Proceedings of the National Academy of Sciences of the United States of America. 96, 12394-12399

78 Zhang, P., Ye, F., Bastidas, A. C., Kornev, A. P., Wu, J., Ginsberg, M. H. and Taylor, S. S. (2015) An Isoform-Specific Myristylation Switch Targets Type II PKA Holoenzymes to Membranes. Structure. 23, 1563-1572

79 Boshart, M., Weih, F., Nichols, M. and Schutz, G. (1991) The tissue-specific extinguisher locus TSE1 encodes a regulatory subunit of cAMP-dependent protein kinase. Cell. 66, 849-859

80 Jones, K. W., Shapero, M. H., Chevrette, M. and Fournier, R. E. (1991)

Subtractive hybridization cloning of a tissue-specific extinguisher: TSE1 encodes a regulatory subunit of protein kinase A. Cell. 66, 861-872

81 Kirschner, L. S., Carney, J. A., Pack, S. D., Taymans, S. E., Giatzakis, C., Cho, Y. S., Cho-Chung, Y. S. and Stratakis, C. A. (2000) Mutations of the gene encoding the protein kinase A type I-alpha regulatory subunit in patients with the Carney complex. Nat Genet. 26, 89-92

82 Beuschlein, F., Fassnacht, M., Assie, G., Calebiro, D., Stratakis, C. A., Osswald, A., Ronchi, C. L., Wieland, T., Sbiera, S., Faucz, F. R., Schaak, K., Schmittfull, A., Schwarzmayr, T., Barreau, O., Vezzosi, D., Rizk-Rabin, M., Zabel, U., Szarek, E., Salpea, P., Forlino, A., Vetro, A., Zuffardi, O., Kisker, C., Diener, S., Meitinger, T., Lohse, M. J., Reincke, M., Bertherat, J., Strom, T. M. and Allolio, B. (2014) Constitutive 
activation of PKA catalytic subunit in adrenal Cushing's syndrome. N Engl J Med. 370, $1019-1028$

83 Stratakis, C. A. (2002) Mutations of the gene encoding the protein kinase A type I-alpha regulatory subunit (PRKAR1A) in patients with the "complex of spotty skin pigmentation, myxomas, endocrine overactivity, and schwannomas" (Carney complex). Annals of the New York Academy of Sciences. 968, 3-21

84 Gold, M. G., Gonen, T. and Scott, J. D. (2013) Local cAMP signaling in disease at a glance. J Cell Sci. 126, 4537-4543

85 Gotz, F., Roske, Y., Schulz, M. S., Autenrieth, K., Bertinetti, D., Faelber, K., Zuhlke, K., Kreuchwig, A., Kennedy, E. J., Krause, G., Daumke, O., Herberg, F. W., Heinemann, U. and Klussmann, E. (2016) AKAP18:PKA-RIIalpha structure reveals crucial anchor points for recognition of regulatory subunits of PKA. Biochem J. 473, $1881-1894$

86 Sarma, G. N., Moody, I. S., Ilouz, R., Phan, R. H., Sankaran, B., Hall, R. A. and Taylor, S. S. (2015) D-AKAP2:PKA RII:PDZK1 ternary complex structure: insights from the nucleation of a polyvalent scaffold. Protein science : a publication of the Protein Society. 24, 105-116

87 Gold, M. G., Smith, F. D., Scott, J. D. and Barford, D. (2008) AKAP18 contains a phosphoesterase domain that binds AMP. Journal of molecular biology. 375, 1329-1343 88 Tulsian, N. K., Krishnamurthy, S. and Anand, G. S. (2017) Channeling of cAMP in PDE-PKA Complexes Promotes Signal Adaptation. Biophysical journal. 112, 25522566 
89 Koschinski, A. and Zaccolo, M. (2015) A novel approach combining real-time imaging and the patch-clamp technique to calibrate FRET-based reporters for cAMP in their cellular microenvironment. Methods Mol Biol. 1294, 25-40

90 Sample, V., DiPilato, L. M., Yang, J. H., Ni, Q., Saucerman, J. J. and Zhang, J. (2012) Regulation of nuclear PKA revealed by spatiotemporal manipulation of cyclic AMP. Nature chemical biology. 8, 375-382

91 Rich, T. C., Xin, W., Mehats, C., Hassell, K. A., Piggott, L. A., Le, X., Karpen, J. W. and Conti, M. (2007) Cellular mechanisms underlying prostaglandin-induced transient cAMP signals near the plasma membrane of HEK-293 cells. Am J Physiol Cell Physiol. 292, C319-331

92 Viste, K., Kopperud, R. K., Christensen, A. E. and Doskeland, S. O. (2005) Substrate enhances the sensitivity of type I protein kinase a to cAMP. The Journal of biological chemistry. 280, 13279-13284

93 Lignitto, L., Carlucci, A., Sepe, M., Stefan, E., Cuomo, O., Nistico, R., Scorziello, A., Savoia, C., Garbi, C., Annunziato, L. and Feliciello, A. (2011) Control of PKA stability and signalling by the RING ligase praja2. Nat Cell Biol. 13, 412-422

94 Wiley, J. C., Wailes, L. A., Idzerda, R. L. and McKnight, G. S. (1999) Role of regulatory subunits and protein kinase inhibitor $(\mathrm{PKI})$ in determining nuclear localization and activity of the catalytic subunit of protein kinase A. The Journal of biological chemistry. 274, 6381-6387 
$\begin{array}{llll}\text { A } & \text { B } & \text { C } & \text { D }\end{array}$

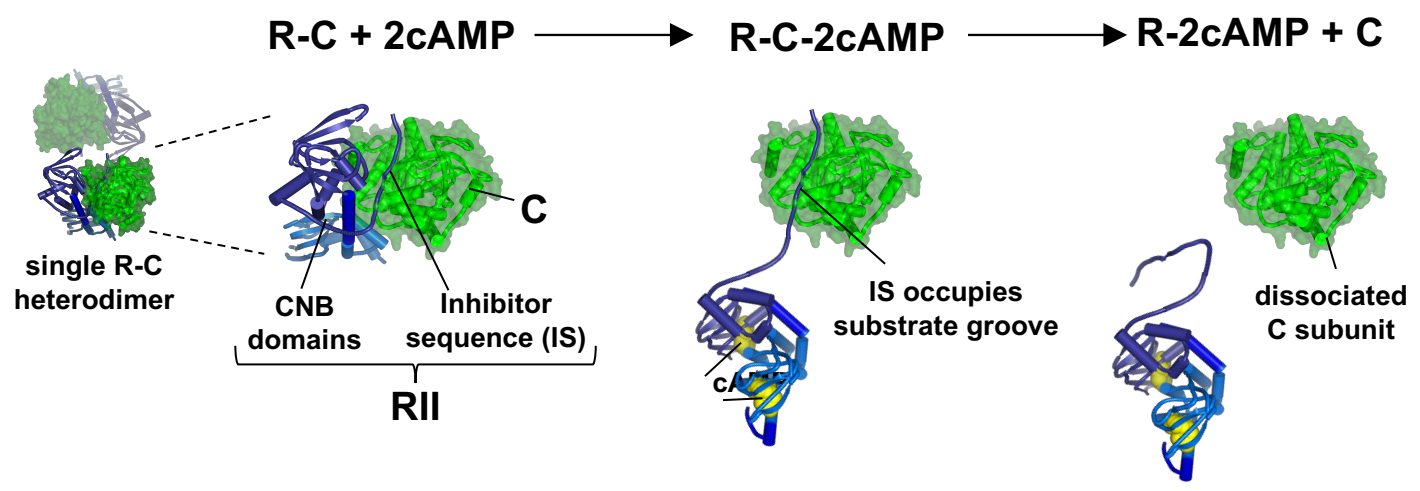

\section{Activated RII-C fusion}

substrate groove available-

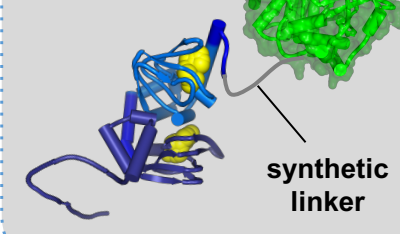


A
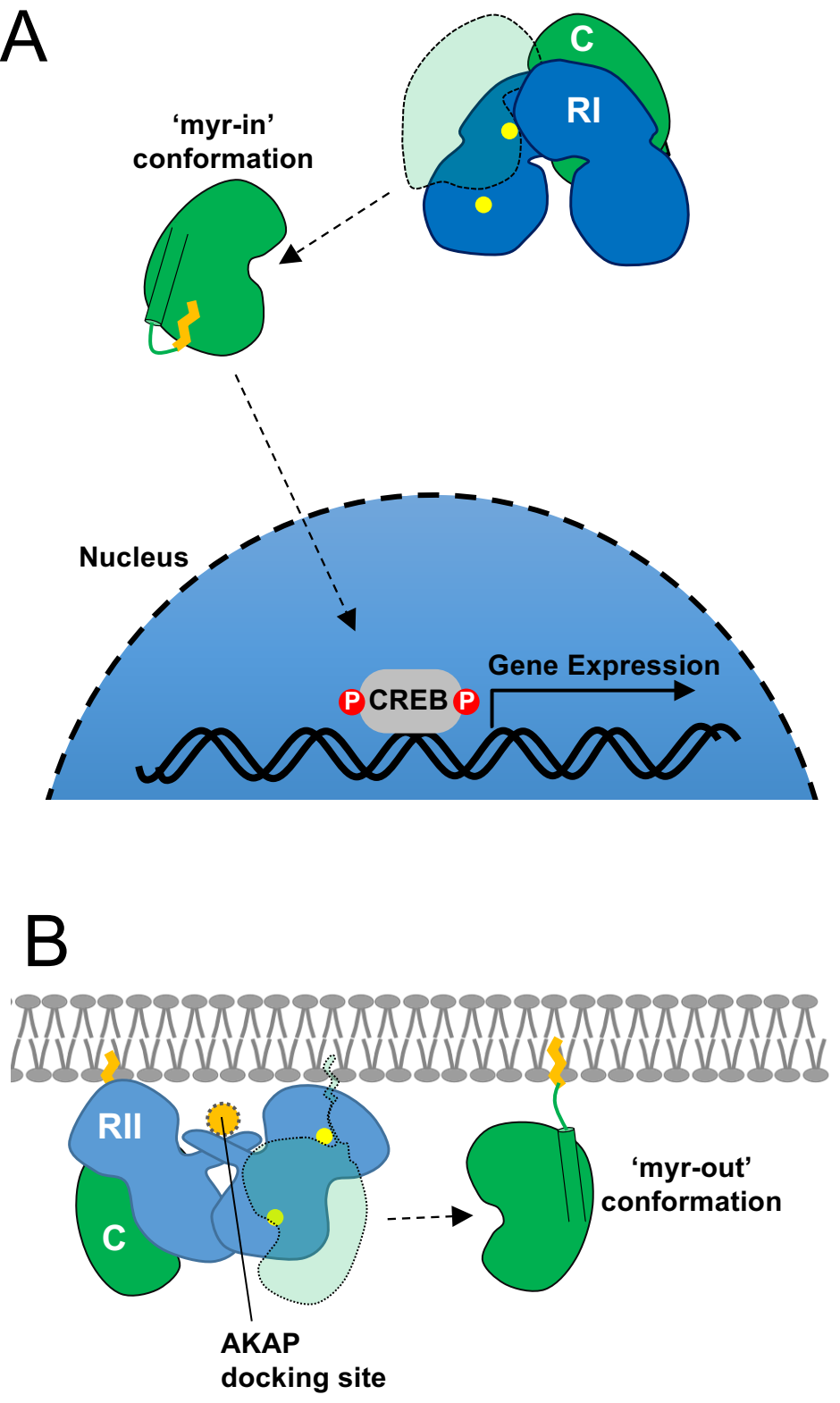

Figure 2 